\section{Pacific Northwest}

National Laboratory

Operated by Battelle for the

U.S. Department of Energy

\title{
Implantation and Release of Krypton with Copper Foils
}

\author{
B. M. Oliver \\ G. C. Eiden \\ N. E. Ballou
}

September 2001

Prepared for the U.S. Department of Energy under Contract DE-AC06-76RL01830 


\title{
Implantation and Release of Krypton with Copper Foils
}

\author{
B. M. Oliver \\ G. C. Eiden \\ N. E. Ballou
}

September 2001

Prepared for the U.S. Department of Energy

under Contract DE-AC06-76RLO 1830

Pacific Northwest National Laboratory

Richland, Washington 99352 


\section{Summary}

A system and a method providing high-efficiency implantation and release of $\mathrm{Kr}$ ions in metal foils have been developed. Implantation and release measurements were performed with a static mass spectrometer. Efficient implantation/retention of rare-gas isotopic ions in a target and their subsequent efficient volatilization from the target is the first of two central requirements for developing an ultrasensitive (10 parts per trillion) method to determine the isotopic content of rare gases. In a number of initial $\mathrm{Kr}$ ion implantation runs in $\mathrm{Cu}$, with subsequent volatilization of the implanted $\mathrm{Kr}$ by heating, implantation/release efficiencies averaging about 52\% were observed. This low value was determined to be due to only partial interception of the $\mathrm{Kr}$ ion beam by the target. With modifications to the target assembly, mass spectrometer, and target size, the efficiencies for implantation/release of $\mathrm{Kr}$ in $\mathrm{Cu}$ were raised to essentially $100 \%$. These efficiencies meet the first requirement for developing this method.

Further experiments were conducted to determine at what increasing values of $\mathrm{Kr}$ ion fluence implantation efficiencies would start to fall below $100 \%$ as a result of ion beam/target processes (e.g., sputtering effects, $\mathrm{Kr}$ diffusion and radiation damage in the $\mathrm{Cu}$ target). In the three highest fluence runs, the implantation/retention efficiency decreased from $88 \%$ down to $28 \%$ for increasing fluence values. From these data, it was calculated that the threshold for a loss in efficiency was at a fluence of about $2 \times 10^{14}$ ions $/ \mathrm{cm}^{2}$.

With the successful development of a method for $100 \%$ efficiency in implantation/release of $\mathrm{Kr}$ ions in $\mathrm{Cu}$, the second requirement for developing an ultrasensitive method to determine the isotopic content of rare gases can now be addressed. High-efficiency isotopic separation and measurement methods for rare-gas ions by static mass spectrometric techniques will be developed. 


\section{Acknowledgments}

The authors would like to acknowledge the assistance of Mr. Stanley Bos with the operation and re-configuration of the 6-60 mass spectrometer. We would also like to thank Dr. David C. Gerlach for performing the SIMS analyses. We express our appreciation to S.A. Schubert, the program manager. The project is funded by the DOE/Office of Nonproliferation Research and Engineering (NN-20). Pacific Northwest National Laboratory is operated for the U.S. Department of Energy by Battelle under Contract DE-AC06-76RL01830. 


\section{Contents}

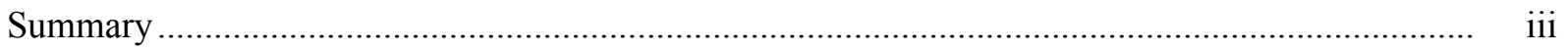

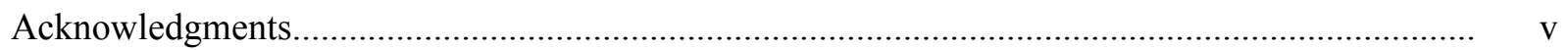

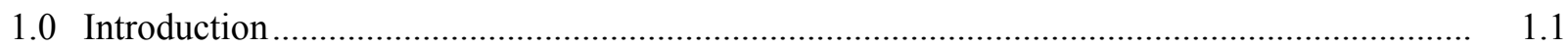

2.0 Krypton Implantation and Release Measurements........................................................ 2.1

2.1 Ion Implantation and Release System …............................................................... 2.1

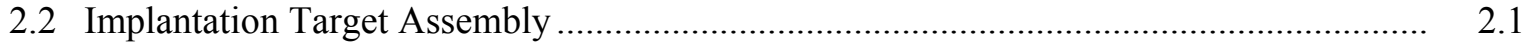

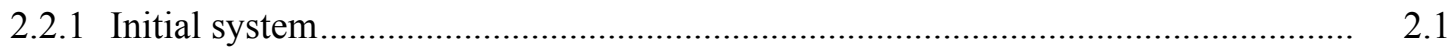

2.2.2 Load-Lock Button Heater System ............................................................... 2.2

2.3 Experimental Setup for Target Implantation and Release ............................................ 2.4

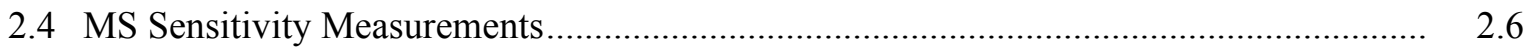

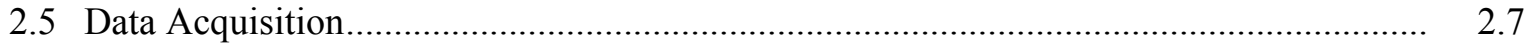

2.6 Implantation and Release Measurements - Phase 1 .................................................... 2.7

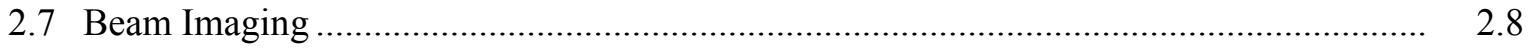

2.8 Implantation and Release Measurements - Phase 2 ................................................ 2.10

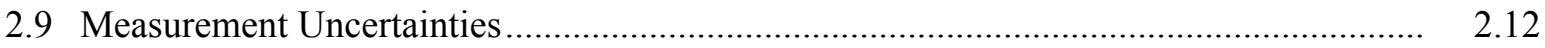

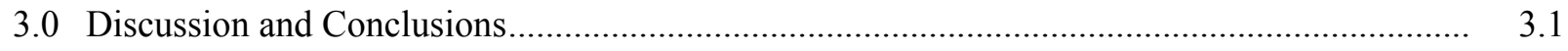

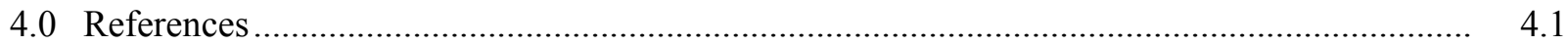




\section{Tables}

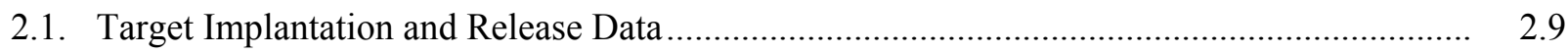

2.2. Sources of Bias and Imprecision in Kr Implantation/Release Measurements ........................ 2.14

\section{Figures}

2.1. Diagram of Rear Load-Lock Chamber with Target and Heater Assembly ........................... 2.3

2.2. Photograph of Original Button-Heater Target Assembly …................................................ 2.3

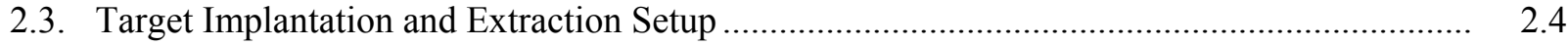

2.4. Typical Beam Current Profile as Measured by the FC During Target Implantation ............... $\quad 2.5$

2.5. Measured Krypton Release Fraction Versus Implant Dose for Original Copper Target at $\sim 11.7 \mathrm{~cm}(\sim 4.6$ in.) Behind the Faraday Cup Assembly ................................................ 2.8

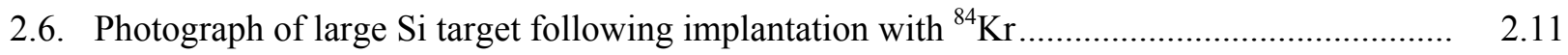

2.7. Modified "Floating" Button-Heater and Rod Assembly, with the Larger $\mathrm{Cu}$ Target Shown on the Right-Hand Side

2.8. Measured Krypton Release Fraction Versus Implant Dose and Fluence for the Larger Copper Target at $\sim 1.27 \mathrm{~cm}(\sim 0.5$ in.) Behind the Faraday Cup Assembly.... 


\subsection{Introduction}

Determinations of rare isotopes of rare gases (e.g., ${ }^{3} \mathrm{He},{ }^{39} \mathrm{Ar},{ }^{81,85} \mathrm{Kr}$ ) provide a sensitive means for 1) age dating groundwaters and polar ice sheets (Chen et al. 1999; Collon et al. 1997; Collon et al. 1999; Collon et al. 2000; IAEA 1992; Ocker and Thonnard 1997; Oeschger 1987; Petit et al. 1999; Thonnard 1995; Wendt et al. 2000), 2) studying transport processes in the ocean, atmosphere and groundwater (Bailey et al. 2000; Chen et al. 1999; IAEA 1992; Kramer et al. 1986; Payne et al. 1994; Wendt et al. 2000), 3) monitoring nuclear-fuel reprocessing activities (Nakleh et al. 1997; Poths and Chamberlin 1995; von Hippel et al. 1985; Wendt et al. 2000), and 4) detecting solar neutrinos (Bahcall and Ulrich 1988; Davis et al. 1989). In this report, progress in a project to develop a method for ultrasensitive (10 parts per trillion) determination of isotopic content of rare gases is provided. The method being developed is based on static isotope separation and measurement. In this approach, a rare gas is held in a closed vacuum system in which ions of rare-gas isotopes are generated continuously, and the isotopic ions are separated by electric and/or magnetic means. Separated isotopic ions are implanted and collected on individual target foils (or alternative materials). After sufficient isotopic material of interest has accumulated in a given target, all of the remaining rare gas in the system is pumped out. Then the isotope of interest that is implanted in the target is volatilized from the target into the closed system by heating or other means. The isotopic abundance of the isotope of interest is then measured with the system's isotope separating and measurement capabilities.

Development of techniques for efficient implantation/retention of rare-gas isotopic ions in a target and for their subsequent efficient volatilization from the target is a first requirement for the method. Then a highly efficient isotope separation system must be established to permit ultrasensitive isotopic separations and measurements. Early experiments showed the feasibility of implantation of $\mathrm{Ar}$ and $\mathrm{Kr}$ in $\mathrm{Al}$ foils and of releasing them by heating (Ballou 1999). Optimization and quantification of the processes were needed and were studied next with $\mathrm{Kr}$ ions on a $\mathrm{Cu}$ target.

In the following, the development of systems and processes that provided efficiencies of essentially $100 \%$ in both the $\mathrm{Kr}$ ion implantation step and in the volatilization/release step is described. In these studies, determinations were also made of the extent of reduction in the retention efficiency of implanted $\mathrm{Kr}$ ions with increasing fluence of ions on a $\mathrm{Cu}$ target. 


\subsection{Krypton Implantation and Release Measurements}

\subsection{Ion Implantation and Release System}

Implantation and release efficiency have been measured using a commercial static gas mass spectrometer, a "6-60," manufactured by the Nuclide Corporation (now Spectrumedix, Inc., State College, PA). The mass analyzer consists of a single magnetic sector field in which the ions are bent through an angle of $60^{\circ}$ as they pass through the magnetic field. The radius of curvature of the ion's flight path in the magnet is $\sim 15.2 \mathrm{~cm}$ ( $\sim 6$ in.), hence, the spectrometer's designation as "6-60." There were originally two ion detectors, a Faraday Cup (FC) and an electron multiplier (EM). The FC is located between the exit slit and the EM. The FC is moved aside when EM measurements are to be made. In the present work, the EM was removed so an implantation target can take its place.

The ion source is a partially sealed Nier style (Nier 1940) electron impact source. Gas enters the source through a tube and exits through the ion extraction slits; the gas conductance into and out of the source is thus limited such that in dynamic mode there is a significant pressure difference between the interior of the ion source and the flight tube.

The efficiency of such ion sources is often stated in terms of the extractable ion current for a given gas pressure; this instrument's efficiency is approximately $0.001 \mathrm{Amp} /$ Torr. Note that this efficiency refers to static mode operation. This is important in the present work since it is desired to operate at highbeam current during the implantation step. This in turn requires a high sample gas pressure. But high pressure degrades the abundance sensitivity of the mass analyzer. There is thus an optimum pressure with respect to the speed of analysis and mass-separation efficacy. In the present work, the typical operating pressure for ion implantation was $2 \times 10^{-6}$ Torr in the flight tube (uncorrected ion gauge reading for $\mathrm{Kr}$ ); further details of the experimental method are given below.

Target materials were selected from metallic foils with conveniently attainable melting points (less than about $1500^{\circ} \mathrm{C}$ ). The choice of metal was restricted in this way in case it became necessary to heat the foils to near their melting points to obtain complete release of $\mathrm{Kr}$ (Carter and Colligon 1968; Carter et al. 1980). The first material chosen was Al foil. But at the time of these early experiments, our heating apparatus was inadequate, and no release was observed. The second material chosen was $\mathrm{Cu}$ foil with a melting point of $1063^{\circ} \mathrm{C}$. Literature information on $\mathrm{Kr}$ ion bombardment of $\mathrm{Cu}$ is available (Carter and Colligon 1968; Carter et al. 1980), which provides guidance and can be compared to the present results.

\subsection{Implantation Target Assembly}

\subsubsection{Initial system}

To allow for krypton ion implantation and subsequent release from selected target materials, several target/heater assemblies were initially constructed. One system was built by McAllister Associates (Coeur d'Alene, ID); it was tested in its heating mode and found to be inadequate for several reasons. First, the heating efficiency was insufficient to reach the desired foil temperatures. Second, the outgassing rate was very high. This might have been alleviated if much higher temperatures could have been achieved such that an initial de-gassing could be done before implantation. Third, the rhenium heating 
element interacted with the background gases (active metal reacts with $\mathrm{N}_{2}, \mathrm{O}_{2}, \mathrm{H}_{2} \mathrm{O}$, etc., especially at elevated temperature), leading to large and unpredictable swings in pressure as various heating profiles were used to release implanted gas.

One advantage of the McAllister unit, however, was that the target could be cooled during implantation. Thus, the design allowed for liquid nitrogen cooling of the target assembly, which significantly complicated the design. It was thought at first that that target should be able to be cooled to cryogenic temperatures during implant and then heated to release the implanted gas. It was also thought that cooling might be important with some targets in order to minimize diffusion during the implantation. However, diffusion during implantation has not proven to be a problem in the experiments with $\mathrm{Cu}$ targets described below (targets at room temperature during implantation). Relaxing the cooling requirement in the target design allowed for a much simpler system. The target should also be electrically isolated so that the impinging ion beam current could be monitored or the target biased at high voltage to increase the ion implantation energy.

Radiative heating of metal foils was also tested using a radiant lamp as the heat source. Preliminary tests show no evidence of gas release. This was not surprising in retrospect, given the low efficiency with which energy will be absorbed by highly polished metal surfaces and the available power (300 Watt lamp).

\subsubsection{Load-Lock Button Heater System}

To alleviate problems encountered in the initial systems, an improved system was designed around a commercially available button heater assembly attached to a "load-lock" gas manifold to allow for quick changing of the target and or target assembly without the need to vent the mass spectrometer. The gas manifold accomplished two things: the mass spectrometer could be evacuated and returned to baseline background after the ion implantation step, and the released gas could be scrubbed of interfering gases before mass analysis. A diagram of the load-lock system is given in Figure 2.1.

The button heater was mounted to a $45.7 \mathrm{~cm}$ (18 in.) long by $1.27 \mathrm{~cm}(0.5 \mathrm{in}$.) diameter stainless steel rod attached to an o-ring sealing fixture at the rear part of the assembly, which allowed for horizontal movement of the heater and target into and out of the detector volume of the 6-60. This crude rotary, linear motion feedthrough results in some leakage of room air into the rear chamber when the target is moved or rotated, but acquisition of a high-vacuum commercial feedthrough was beyond the budget constraints of the project. With adequate scrubbing of the released gas before mass analysis, however, acceptable data can be obtained. The main limitation imposed by the poor vacuum integrity of the linear/rotary motion feedthrough is that the system must be pumped out for several hours after each movement of the feedthrough, increasing the time required to perform each implant/release measurement.

A photograph of the heater/target assembly is shown in Figure 2.2. The button heater's manufacturer (HeatWave, Watsonville, CA) states that the heater is capable of achieving surface temperatures up to $1200^{\circ} \mathrm{C}$ over a circular area of $1.27 \mathrm{~cm}(0.5 \mathrm{in}$.) diameter. Our measurements of button temperature (data not shown) are consistent with this claim. Various types of metal foil material can be held to the front face of the heater using available tantalum heater caps, which provided an exposed foil area to the beam of $\sim 1.0 \mathrm{~cm}$ ( $\sim 0.4$ in.) diameter. On-bench alignment of the target was conducted using a double-sided conflat vacuum fitting with viton-gaskets instead of the usual copper. With the viton gaskets, the unit 
acted as a simple gimbal assembly and allowed for small x,y adjustment of the target when in the implant position.

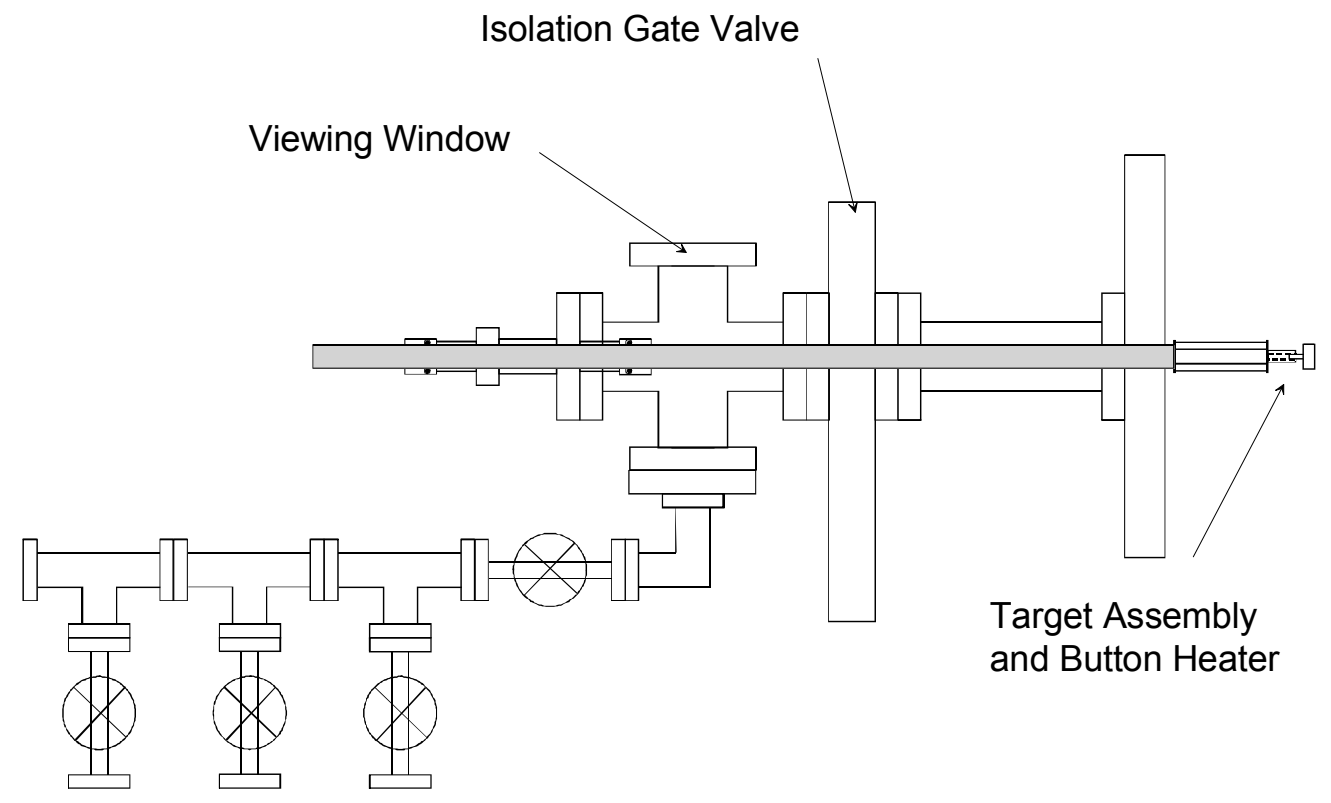

Getters

Figure 2.1. Diagram of Rear Load-Lock Chamber with Target and Heater Assembly

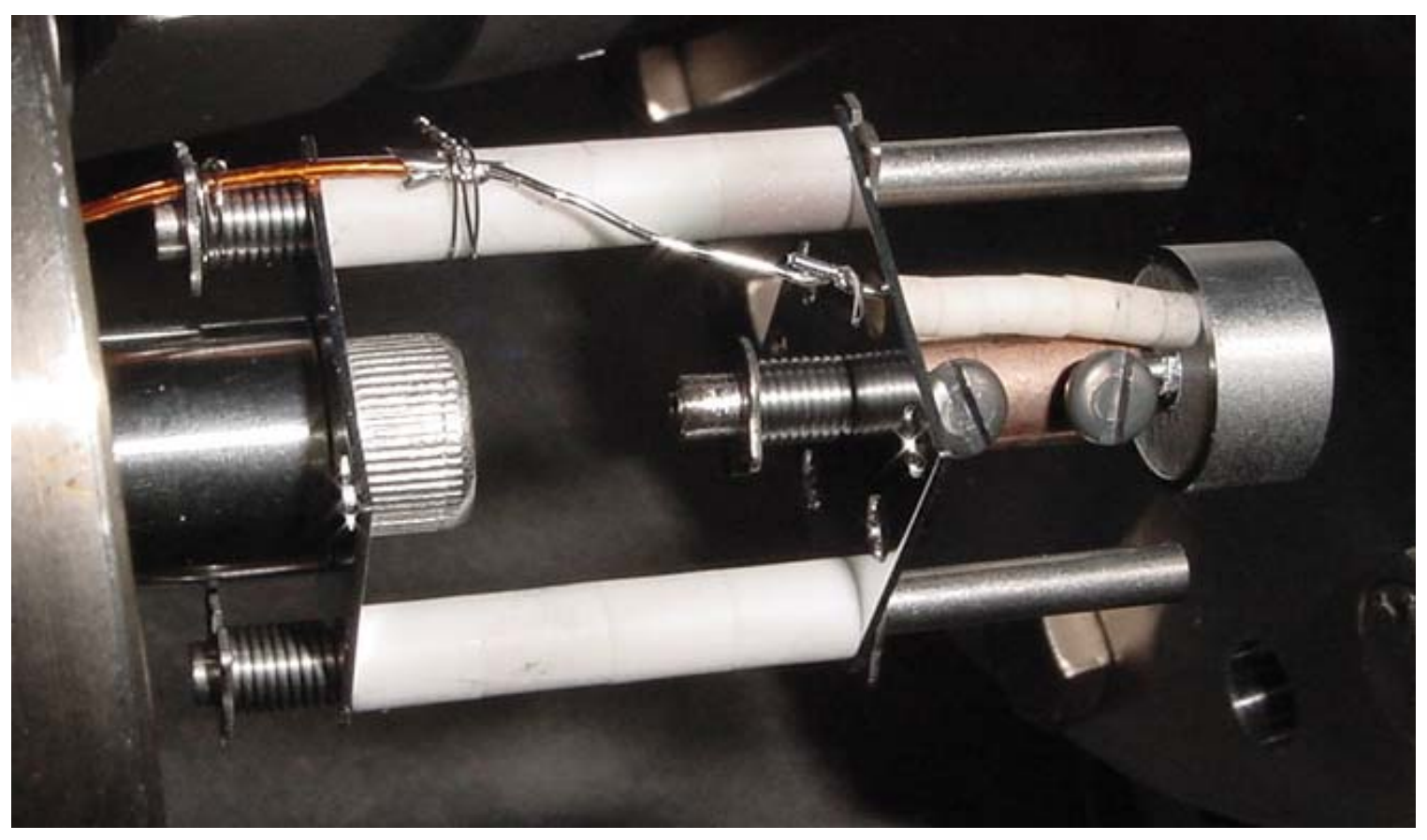

Figure 2.2. Photograph of Original Button-Heater Target Assembly. The Ta cap that holds the $\mathrm{Cu}$ foil target fits over the heater on the far right. 
As shown in Figure 2.1, the heater could be physically isolated from the detector region of the 6-60 by means of a gate valve when retracted. An electrical connection to one side of the button heater went through a coiled section of Kapton-insulated wire that exited through the bottom side of the assembly. The other side of the heater was connected to the rod assembly and thus was physically grounded to the 660 system. Also attached to the rear part of the chamber are two SAES (SAES Getters USA Inc., Colorado Springs, CO) getter pumps that pump active gases, but not rare gases.

\subsection{Experimental Setup for Target Implantation and Release}

The general experimental setup for the implantation and extractions is shown in Figure 2.3. Implantation and release measurements using the improved assembly were all conducted at a target location approximately $1.3 \mathrm{~cm}(0.5 \mathrm{in}$.) behind the exit slit for the Ion Retarding Lens assembly (RL). This corresponded to a distance of $\sim 12 \mathrm{~cm}(\sim 4.6 \mathrm{in}$.) from the exit of the Faraday Cup (FC) assembly, and was the approximate location of the entrance plate for the original 6-60 electron multiplier detector that was removed for the present work. The exit slit of the spectrometer is $2.8 \mathrm{~cm}(1.1 \mathrm{in}$.) further away from the target. The target-to-spectrometer exit-slit distance is thus $\sim 14 \mathrm{~cm}(5.7 \mathrm{in}$.).

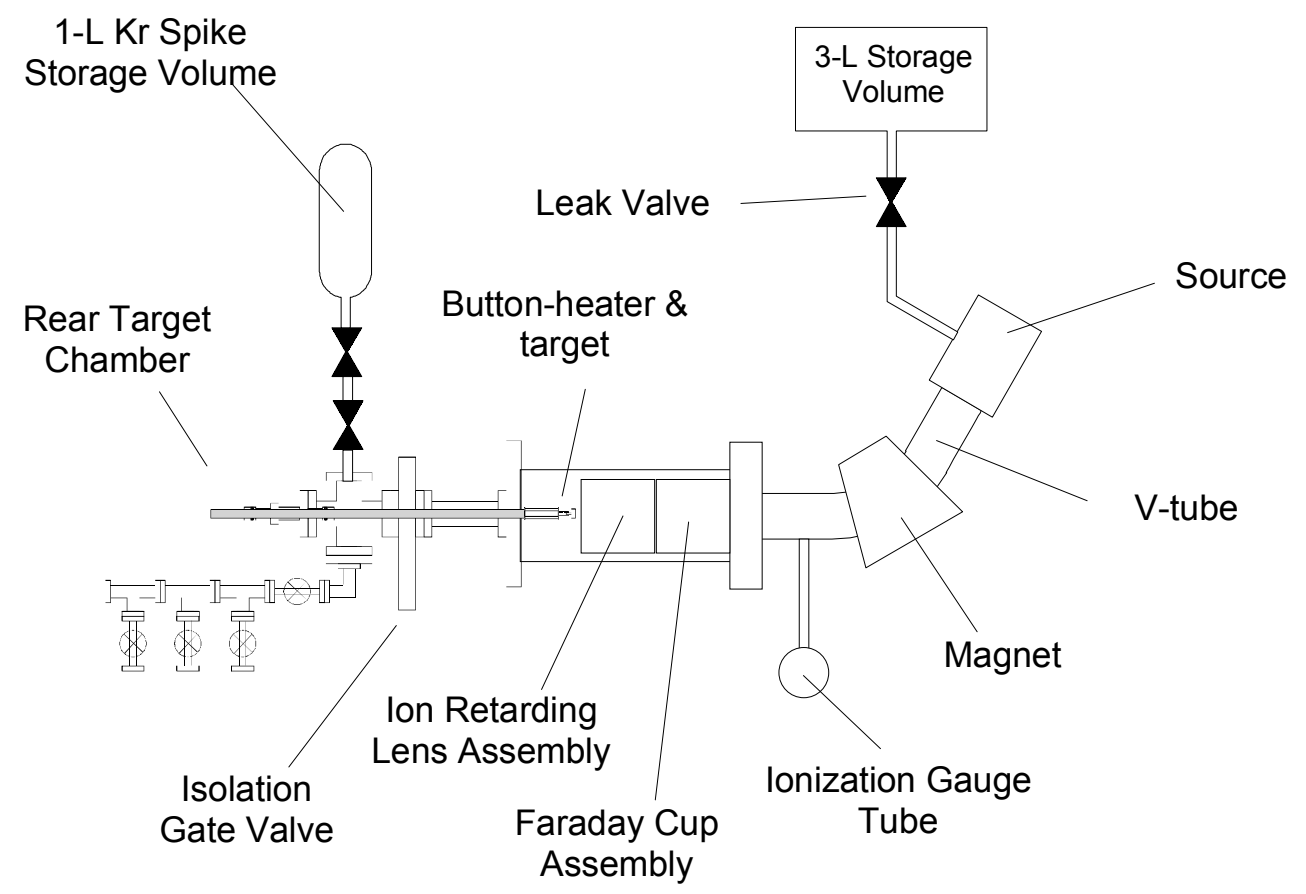

Figure 2.3. Target Implantation and Extraction Setup

In summary, the measurement protocol was as follows. The target was moved into the detector volume at a location approximately $12 \mathrm{~cm}$ (4.6 in.) behind the exit of the FC assembly. After allowing for sufficient system pumpdown after target movement (generally several hours), the 6-60 was tuned to mass 84, and a $\mathrm{Kr}$ beam was established by bleeding in a controlled amount of $\mathrm{Kr}$ from the storage volume through the adjustable UHV leak valve. For the implantations, the 6-60 was operated in dynamic mode, 
with the spectrometer turbopump isolation valves open. This was done to allow for maximum beam currents to be generated while still maintaining the flight-tube section of the 6-60 at a sufficiently high vacuum $\left(\sim 10^{-6}\right.$ Torr or lower) for acceptable mass-spectrometer performance.

The Kr signal from the FC was monitored and recorded onto a continuous data file using a data acquisition system (DAS) as discussed later. The FC was retracted after stabilizing the $\mathrm{Kr}$ signal, allowing the $\mathrm{Kr}$ beam to impact the copper-foil target. After the desired duration of implantation, the FC was re-inserted into the beam, and the beam current was again recorded on the data file. One such data file is displayed in Figure 2.4. The curve connecting the beginning and end points for the monitored beam current is a best fit to the data and was used to determine the total integrated ion dose (see Section 2.9). A later modification to the target assembly allowed for direct monitoring of the target current during the period the FC was retracted. Following implantation, the target was retracted into the rear chamber section of the assembly, the isolation gate valve was closed, and the chamber and 6-60 were pumped overnight (or longer) to prepare for thermal extraction and measurement of the implanted Kr. Depending on the particular implantation/release run, other data were recorded on the DAS, including vacuum ionization gauge pressure, button-heater voltage, and target-beam current (for the later target-assembly modification, see the discussion below).

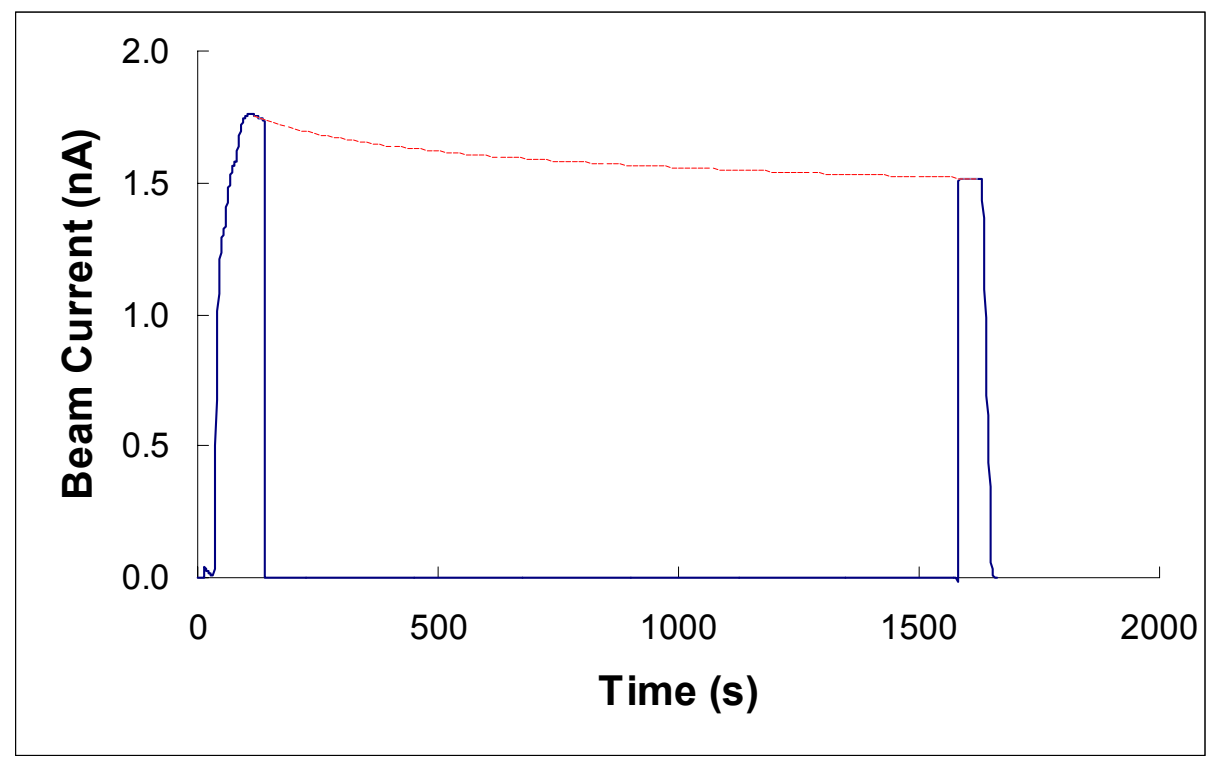

Figure 2.4. Typical Beam Current Profile as Measured by the FC During Target Implantation. The central curve is an approximation to the actual target current using a power-law fit.

The $\mathrm{Kr}$ was released from the target by heating the button heater and target foil. Generally, an initial "blank" run was conducted to verify acceptable Kr background. This was followed by the actual "release" run, and then generally a "re-heat" run, to determine the Kr background under heating conditions. The "re-heat" run was also used to verify negligible Kr remaining in the target after the "release" run. After installing a Kr spiking system (see below), the re-heat run was followed by a run to determine the mass spectrometer's sensitivity. The "release," "blank," "re-heat," and "sensitivity" runs 
were all done in static mode. For the release and re-heat runs, the rear chamber was first isolated from its vacuum pump. The button heater was then heated for between 5 to $10 \mathrm{~min}$. and then allowed to cool for approximately $5 \mathrm{~min}$. At some stage in the cooling step, the 6-60 was also put in static mode, and the background buildup of $\mathrm{Kr}$ was recorded on the DAS. Following the target cooling step, the gate valve was opened, and the released $\mathrm{Kr}$ from the target was allowed to expand into the 6-60 system. The increased signal from the FC was again recorded. Generally, both $\mathrm{Kr}-84$ and $\mathrm{Kr}-86$ were monitored, with the $\mathrm{Kr}-86$ signal being used to determine the contribution from natural $\mathrm{Kr}$ outgassing from the rear chamber and 6-60. A correction was also made for back expansion of $\mathrm{Kr}$ buildup in the 6-60 into the back chamber. This correction was typically much less than $1 \%$ of the net release signal. A similar protocol was used for the initial blank run, except that the button heater was not heated.

\subsection{MS Sensitivity Measurements}

During implantation, the number of $\mathrm{Kr}$ atoms implanted was calculated in a straightforward manner from the FC current recorded immediately preceding and following the implantation. Recording of the beam current during implantation was not possible with the initial target setup as the button heater was electrically grounded inside the 6-60. At a later stage in the experimental measurements, a modification to the target assembly was conducted (see Section 2.8), which allowed the target to "float" and thus permitted approximate monitoring of the current flow to the target during implantation.

Determining the number of atoms of $\mathrm{Kr}$ released from the targets, however, required a knowledge of the absolute $\mathrm{Kr}$ sensitivity of the 6-60 system while in static-mode operation. This sensitivity was initially determined by relating the observed pressure rise in the ionization gauge (attached to the flight tube near the exit slit) during target implantation to the observed beam current from the FC and yielded values of approximately $5 \times 10^{-3} \mathrm{~A} /$ Torr for $\mathrm{Kr}$. Using this sensitivity, calculated $\mathrm{Kr}$ releases from the targets were very low, of the order of $<1 \%$ of the implanted amounts. Additional investigation determined that this sensitivity value was artificially high due to significant pressure differences that existed between the 6-60 source chamber and the flight tube during dynamic-mode operation.

In order to accurately determine the sensitivity of the 6-60 for $\mathrm{Kr}$ in static mode, it was decided to develop a simple Kr "spiking" system. The system, which is also shown in Figure 2.3, consisted of a 1-L spike storage bottle filled to a low pressure of $\mathrm{Kr}$ gas. Attached to the end of the bottle are two highvacuum valves connected in series, with a small volume in between. Small known amounts ("aliquots") of $\mathrm{Kr}$ can be dispensed from the bottle by expanding and then trapping a small fraction of the $\mathrm{Kr}$ gas in the volume between the two valves. The level of $\mathrm{Kr}$ in each aliquot was determined by first accurately measuring the volume of the bottle and the volume between the two valves and then filling the bottle with an accurately measured low pressure of $\mathrm{Kr}$ gas. The bottle was filled by expanding a larger volume of gas through a succession of measured volumes.

All volume measurements were made using a standard gas-expansion and pressure-drop method. Pressure measurements for the volume calibrations and the gas filling were made on a separate gas manifold with two attached capacitance manometers (Baratron), with the values being cross compared between each manometer. Volume measurements were replicated three times, with reproducibilities of better than $0.4 \%$ in all cases. The $\mathrm{Kr}$ pressure in the 1 - $\mathrm{L}$ spike storage bottle was adjusted during filling to yield $\mathrm{Kr}$ aliquots in the range of $\sim 2 \times 10^{13}$ atoms $\mathrm{Kr}-84$. 


\subsection{Data Acquisition}

Date were initially collected using a simple serial-port data-acquisition system connected to a personal computer (PC). Only a single channel was monitored, the output of the electrometer connected to the 6-60 faraday cup. In later experiments, data collection was switched to a Fluke Hydra system, and two additional data channels were recorded, including pressure data from the ionization gauge attached to the flight tube section of the 6-60, button heater voltage, or the beam current from the modified floating target.

\subsection{Implantation and Release Measurements - Phase 1}

More than 30 implant and release measurements were conducted using the original load-lock target assembly shown in Figure 2.1 and the original copper foil target. The main objectives of these measurements were to 1) establish the efficiency of $\mathrm{Kr}$ ion implantation and release from copper, and 2) determine at what ion implantation fluence (i.e., atoms $/ \mathrm{cm}^{2}$ ) measurable loss of implanted $\mathrm{Kr}$ begins to occur with increasing $\mathrm{Kr}$ ion bombardment. A number of these runs, particularly the initial runs, were conducted as scoping tests to optimize the source, implantation, and release conditions; thus, the results for these runs are not reported here. The results for the remaining runs are given in the first section of Table 2.1 and are also shown graphically in Figure 2.5. All of these runs were conducted at a sourceemission trap current of $100 \mu \mathrm{A}$, an electron ionization energy of $70 \mathrm{eV}$, and an accelerating voltage of $5.0 \mathrm{kV}$. Except for the runs on 2/9/01 and 2/12/01, which were conducted at a slightly increased distance from the $\mathrm{FC}$, the target location for this first series of measurements was fixed at $\sim 12 \mathrm{~cm}$ ( $\sim 4.6 \mathrm{in}$.) behind the FC exit slit.

Initially, the target implantation time was fixed at approximately $10 \mathrm{~min}$. and the beam current varied by changing the setting of the $\mathrm{Kr}$ inlet leak valve. These data are shown as the open squares in Figure 4. Because of later concerns that the beam size might have been varying with the beam current or with source pressure, it was decided to conduct an additional series of runs at a fixed beam current. For these runs, a beam current of $\sim 1.5 \mathrm{nA}$ was chosen to correlate the data from this latter series with earlier data at this same current. The dose/release measurements at $\sim 1.5 \mathrm{nA}$ are shown as open diamonds in Figure 2.5.

All of the release runs listed in Table 2.1 used a steady-state button heater voltage and current of 6.5 V and 2.25 A. For those runs between 1/16/01 and 1/26/01, the maximum initial heater current was set at $2.25 \mathrm{~A}$, and the heater voltage was allowed to slowly increase to the equilibrium value of $6.5 \mathrm{~V}$ as the resistance of the heater element increased with temperature. For the release runs after $1 / 26 / 01$, the maximum initial current was increased to $4.0 \mathrm{~A}$ to allow the ramp up in target temperature to increase at a faster rate. 


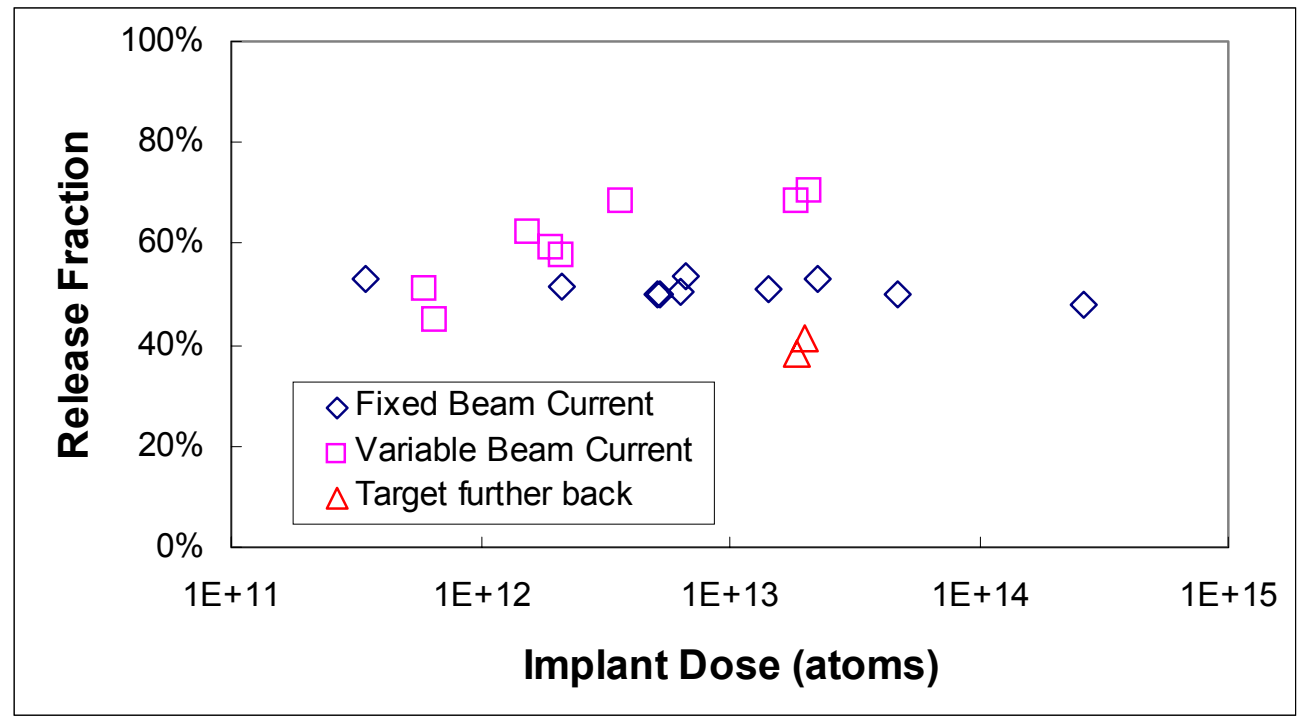

Figure 2.5. Measured Krypton Release Fraction Versus Implant Dose for Original Copper Target at $\sim 12 \mathrm{~cm}$ ( $\sim 4.6$ in.) Behind the Faraday Cup Assembly (note: the two data points indicated by triangles were taken at distances $>12 \mathrm{~cm}[>4.6$ in.])

As is evident in Figure 2.5, the release efficiency for the initial target configuration varied from about 50 to $70 \%$. Most of this variability is evident in the runs conducted at varying beam current. For the runs conducted at a nearly constant beam current of $1.5 \mathrm{nA}$, the release fraction was essentially constant at an average value of $\sim 52 \%$. Since there was no evidence of saturation of the implant beam, the variation at non-constant beam current is thought to have occurred from changes in the beam size at the target. As is discussed in more detail below, evidence obtained later indicated that the small target was not completely intercepting the ion beam at the 12-cm (4.6-in.) location. Therefore, an increase or decrease in beam size would have affected the implant dose to the target, and thus, the observed release fraction. The results from the two sets of measurements conducted further away from the FC provide further evidence for such an effect. For these two runs, which were at increasing distance from the FC, the target would be expected to intercept smaller fractions of the ion beam. As Figure 4 shows, the release fractions indeed dropped to $\sim 42 \%$ and $38 \%$, respectively.

\subsection{Beam Imaging}

Because of the limiting release efficiency of about $50 \%$ and the lack of any significant falloff in implantation/release efficiency with increasing $\mathrm{Kr}$ ion dose, it was speculated that the target was partially missing the beam, either because of misalignment or from a significant underestimation of the actual beam size. To qualitatively determine the beam size, several imaging tests were conducted. The first test was conducted using a Lexan target to see if the ion tracks from the $\mathrm{Kr}$ beam could be directly observed using standard track etching methods. The implant conditions were an ion energy of $5 \mathrm{KeV}$ and a beam current of $\sim 1.5 \mathrm{nA}$ for a total time of $\sim 1 \mathrm{~h}$ ( $\mathrm{Kr}$ dose $\sim 3 \times 10^{13}$ atoms). Standard etching of the target with a $6 \mathrm{~N}$ sodium hydroxide solution yielded no visible ion tracks. 
Table 2.1. Target Implantation and Release Data

\begin{tabular}{|c|c|c|c|c|c|c|c|c|c|c|}
\hline \multirow{2}{*}{\multicolumn{2}{|c|}{ Run Date }} & \multicolumn{2}{|c|}{ Target $^{(\mathrm{a})}$} & \multicolumn{2}{|c|}{ Implant Beam } & \multirow{2}{*}{\multicolumn{3}{|c|}{$\begin{array}{c}\text { Heater } \\
\text { Time (m) }\end{array}$}} & \multirow{3}{*}{$\begin{array}{c}\text { Released } \\
\text { Atoms }\end{array}$} & \multirow{3}{*}{$\begin{array}{c}\text { Release } \\
\text { Fraction (\%) }\end{array}$} \\
\hline & & \multirow{2}{*}{$\begin{array}{l}\text { Size } \\
\text { (in) }\end{array}$} & \multirow{2}{*}{$\begin{array}{l}\text { Pos'n } \\
\text { (in) }\end{array}$} & \multirow{2}{*}{$\begin{array}{c}\text { Current } \\
\text { (nA) }\end{array}$} & \multirow{2}{*}{$\begin{array}{l}\text { Time } \\
\text { (h) }\end{array}$} & & & & & \\
\hline Implant & Release & & & & & $\begin{array}{l}\text { Implant } \\
\text { Atoms }^{(\mathbf{b})}\end{array}$ & \multicolumn{2}{|c|}{ Heat Cool } & & \\
\hline \multicolumn{11}{|c|}{ Original Target and Foil Assembly } \\
\hline $01 / 15 / 01$ & $01 / 16 / 01$ & 0.4 & 4.6 & 0.57 & 0.17 & $2.13 \mathrm{E}+12$ & 15 & 5 & $1.23 \mathrm{E}+12$ & 58 \\
\hline $01 / 16 / 01$ & $01 / 17 / 01$ & 0.4 & 4.6 & 0.44 & 0.17 & $1.57 \mathrm{E}+12$ & 15 & 5 & $9.77 \mathrm{E}+11$ & 62 \\
\hline $01 / 17 / 01$ & $01 / 18 / 01$ & 0.4 & 4.6 & 0.49 & 0.19 & $1.95 \mathrm{E}+12$ & 15 & 5 & $1.15 \mathrm{E}+12$ & 59 \\
\hline $01 / 22 / 01$ & $01 / 23 / 01$ & 0.4 & 4.6 & 0.17 & 0.17 & $6.57 \mathrm{E}+11$ & 15 & 5 & $2.96 \mathrm{E}+11$ & 45 \\
\hline $01 / 23 / 01$ & $01 / 24 / 01$ & 0.4 & 4.6 & 0.17 & 0.17 & $5.94 \mathrm{E}+11$ & 20 & 5 & $3.03 \mathrm{E}+11$ & 51 \\
\hline $01 / 24 / 01$ & $01 / 25 / 01$ & 0.4 & 4.6 & 1.68 & 0.17 & $6.28 \mathrm{E}+12$ & 15 & 5 & $3.17 \mathrm{E}+12$ & 50 \\
\hline $01 / 25 / 01$ & $01 / 26 / 01$ & 0.4 & 4.6 & 1.69 & 0.14 & $5.28 \mathrm{E}+12$ & 15 & 5 & $2.64 \mathrm{E}+12$ & 50 \\
\hline $01 / 26 / 01$ & $01 / 29 / 01$ & 0.4 & 4.6 & 1.68 & 0.14 & $5.14 \mathrm{E}+12$ & 15 & 5 & $2.57 \mathrm{E}+12$ & 50 \\
\hline $01 / 29 / 01$ & $01 / 30 / 01$ & 0.4 & 4.6 & 4.96 & 0.17 & $1.86 \mathrm{E}+13$ & 10 & 5 & $1.28 \mathrm{E}+13$ & 69 \\
\hline $01 / 31 / 01$ & $02 / 01 / 01$ & 0.4 & 4.6 & 4.83 & 0.19 & $2.08 \mathrm{E}+13$ & 10 & 5 & $1.46 \mathrm{E}+13$ & 70 \\
\hline $02 / 01 / 01$ & $02 / 02 / 01$ & 0.4 & 4.6 & 0.95 & 0.17 & $3.71 \mathrm{E}+12$ & 10 & 5 & $2.54 \mathrm{E}+12$ & 69 \\
\hline $02 / 02 / 01$ & $02 / 05 / 01$ & 0.4 & 4.6 & 1.75 & 0.17 & $6.69 \mathrm{E}+12$ & 10 & 5 & $3.57 \mathrm{E}+12$ & 53 \\
\hline $02 / 05 / 01$ & 02/06/01 & 0.4 & 4.6 & 1.68 & 0.61 & $2.24 \mathrm{E}+13$ & 10 & 5 & $1.19 \mathrm{E}+13$ & 53 \\
\hline $02 / 09 / 01$ & $02 / 12 / 01$ & 0.4 & 5.3 & 1.71 & 0.53 & $1.99 \mathrm{E}+13$ & 10 & 5 & $8.27 \mathrm{E}+12$ & 42 \\
\hline $02 / 12 / 01$ & 02/13/01 & 0.4 & 8.1 & 1.73 & 0.50 & $1.85 \mathrm{E}+13$ & 10 & 5 & $7.07 \mathrm{E}+12$ & 38 \\
\hline $02 / 23 / 01$ & $02 / 26 / 01$ & 0.4 & 4.6 & 1.80 & 0.01 & $3.49 \mathrm{E}+11$ & 10 & 5 & $1.85 \mathrm{E}+11$ & 53 \\
\hline $02 / 26 / 01$ & $02 / 28 / 01$ & 0.4 & 4.6 & 1.58 & 0.06 & $2.10 \mathrm{E}+12$ & 10 & 5 & $1.08 \mathrm{E}+12$ & 52 \\
\hline $02 / 28 / 01$ & 03/01/01 & 0.4 & 4.6 & 1.63 & 0.40 & $1.43 \mathrm{E}+13$ & 10 & 5 & $7.32 \mathrm{E}+12$ & 51 \\
\hline 03/01/01 & 03/02/01 & 0.4 & 4.6 & 1.62 & 1.40 & $4.74 \mathrm{E}+13$ & 10 & 5 & $2.38 \mathrm{E}+13$ & 50 \\
\hline 03/05/01 & 03/06/01 & 0.4 & 4.6 & 1.62 & 7.49 & $2.62 \mathrm{E}+14$ & 10 & 5 & $1.25 \mathrm{E}+14$ & 48 \\
\hline \multicolumn{11}{|c|}{ Modified Target Assembly and New Cu Foil Target } \\
\hline $04 / 05 / 01$ & $04 / 06 / 01$ & 0.4 & 0.5 & 1.35 & 0.16 & $4.97 \mathrm{E}+12$ & 10 & 5 & $3.54 \mathrm{E}+12$ & 71 \\
\hline \multicolumn{11}{|c|}{ Larger Cu Target } \\
\hline $\mid 04 / 12 / 01$ & $04 / 13 / 01$ & 0.75 & 0.5 & 1.60 & 0.17 & $5.75 \mathrm{E}+12$ & 10 & 5 & $5.92 \mathrm{E}+12$ & 103 \\
\hline $04 / 13 / 01$ & $04 / 16 / 01$ & 0.75 & 0.5 & 1.69 & 0.17 & $6.18 \mathrm{E}+12$ & 10 & 5 & $6.31 \mathrm{E}+12$ & 102 \\
\hline $04 / 16 / 01$ & $04 / 17 / 01$ & 0.75 & 0.5 & 1.72 & 4.02 & $1.55 \mathrm{E}+14$ & 10 & 5 & $6.91 \mathrm{E}+13$ & 44 \\
\hline $04 / 17 / 01$ & $04 / 17 / 01$ & 0.75 & 0.5 & 1.12 & 1.04 & $2.62 \mathrm{E}+13$ & 10 & 5 & $2.30 \mathrm{E}+13$ & 88 \\
\hline $04 / 18 / 01$ & $04 / 19 / 01$ & 0.75 & 0.5 & 1.17 & 0.06 & $1.44 \mathrm{E}+12$ & 10 & 5 & $1.47 \mathrm{E}+12$ & 102 \\
\hline $04 / 25 / 01$ & $04 / 26 / 01$ & 0.75 & 0.5 & 1.77 & 7.32 & $2.92 \mathrm{E}+14$ & 10 & 5 & $8.16 \mathrm{E}+13$ & 28 \\
\hline
\end{tabular}

The second imaging technique attempted involved implanting $\mathrm{Kr}$ ions in silicon-wafer sections. From other work at PNNL, silicon wafers were known to change color from hydrogen ion implantation, and it was surmised that a similar effect might be observable for rare-gas ions. As a first test, some unimplanted silicon from the same lot that had been hydrogen implanted was placed on the target assembly and exposed to the same beam conditions as the Lexan discussed above. The exposed area of the silicon was close in size to that for the copper target. The results from several tests indicated just discernable images of a rectangular beam that extended off the upper and lower edges of the target. All of 
the implantations were done with ${ }^{84} \mathrm{Kr}$, except for one target that was rotated $\sim 90^{\circ}$ and re-implanted with

${ }^{82} \mathrm{Kr}$ for later attempts at Secondary Ion Mass Spectroscopy (SIMS) analysis (see below).

The fact that the top and bottom portions of the beam could not be discerned reinforced the conclusion that the original copper target had not completely intercepted the $\mathrm{Kr}$ beam. To verify this conclusion, a larger, $\sim 2-\mathrm{cm}(\sim 0.75 \mathrm{in}$.) square section of silicon was cut from a different lot of silicon material and attached to the front surface of one of the button heater Ta caps. This silicon piece was then implanted with ${ }^{84} \mathrm{Kr}$. The silicon piece was from a bare wafer of normal semiconductor-grade material. Visual examination of this larger target following implantation showed a clear rectangular beam with sharp edges on the top and bottom and on one long side and a more diffuse edge on the other long side, as shown in Figure 2.6. Rough measurements on this image gave a beam size of approximately $.25 \times 1.3 \mathrm{~cm}$ ( $0.1 \times 0.5$ in.), clearly larger than the $\sim 1.0$-cm ( $\sim 0.4$-in.) diameter of the exposed section of the copper target. Also, the sharp edge on the right-hand side suggested that this side of the beam was being blocked by some element in the detector section of the 6-60, perhaps in the ion lens assembly located between the $\mathrm{FC}$ and the target. This assembly was eventually removed to allow the target to be moved closer to the $\mathrm{FC}$, and indeed this eliminated the sharp edge on the beam images.

A preliminary SIMS analysis was also conducted on one of the smaller Si targets. The ${ }^{84} \mathrm{Kr}$ proved to be a poor choice for SIMS in that a significant ion peak due to ${ }^{28} \mathrm{Si}_{3}{ }^{+}$interferes with ${ }^{84} \mathrm{Kr}$. It was then attempted to obtain SIMS images of ${ }^{82} \mathrm{Kr}$ implants. The observed SIMS signals appear to be due to molecular and other ion interferences, and no definitive detection of $\mathrm{Kr}$ implanted into silicon has been obtained to date. However, we plan to revisit these measurements and possibly other surface analytical imaging methods to obtain more quantitative measurements of the beam area and lateral and depth profiles.

\subsection{Implantation and Release Measurements - Phase 2}

Based on the results of the beam-imaging efforts, it was decided to modify the target assembly to allow the target to be placed closer to the exit plate of the FC assembly. At this location, it was surmised that the beam size would be sufficiently smaller to allow for complete interception by the $\sim 1.0-\mathrm{cm}(\sim 0.4-$ in.) diameter $\mathrm{Cu}$ foil target. These modifications included:

- replacing the solid target assembly bar with a longer section of SS tubing

- floating the target from ground and running the two power leads through the tubing to an HV conflat flange at the rear of the tube

- removing the ion retarding lens assembly from the 6-60.

These modifications allowed the implantation target to be moved up to the rear of the FC assembly and also allowed for future biasing of the target to achieve varying ion energy and thus implantation depth. A further advantage to floating the target was that the target itself could be used as a crude faraday cup to permit relative monitoring of the beam current during implantation. This latter feature is useful for longer implants to ensure no drop-outs or significant variations in the beam current during the implantation process. It should be noted that such a current measurement is expected to be seriously in error due to secondary charge emission (and the lack of the suppression grid normally used in a well designed FC), but the temporal profile of the implantation current can be precisely determined and this 
signal normalized to the measured FC currents at the beginning and end of the implant procedure to allow for a more precise determination of the implantation dose.

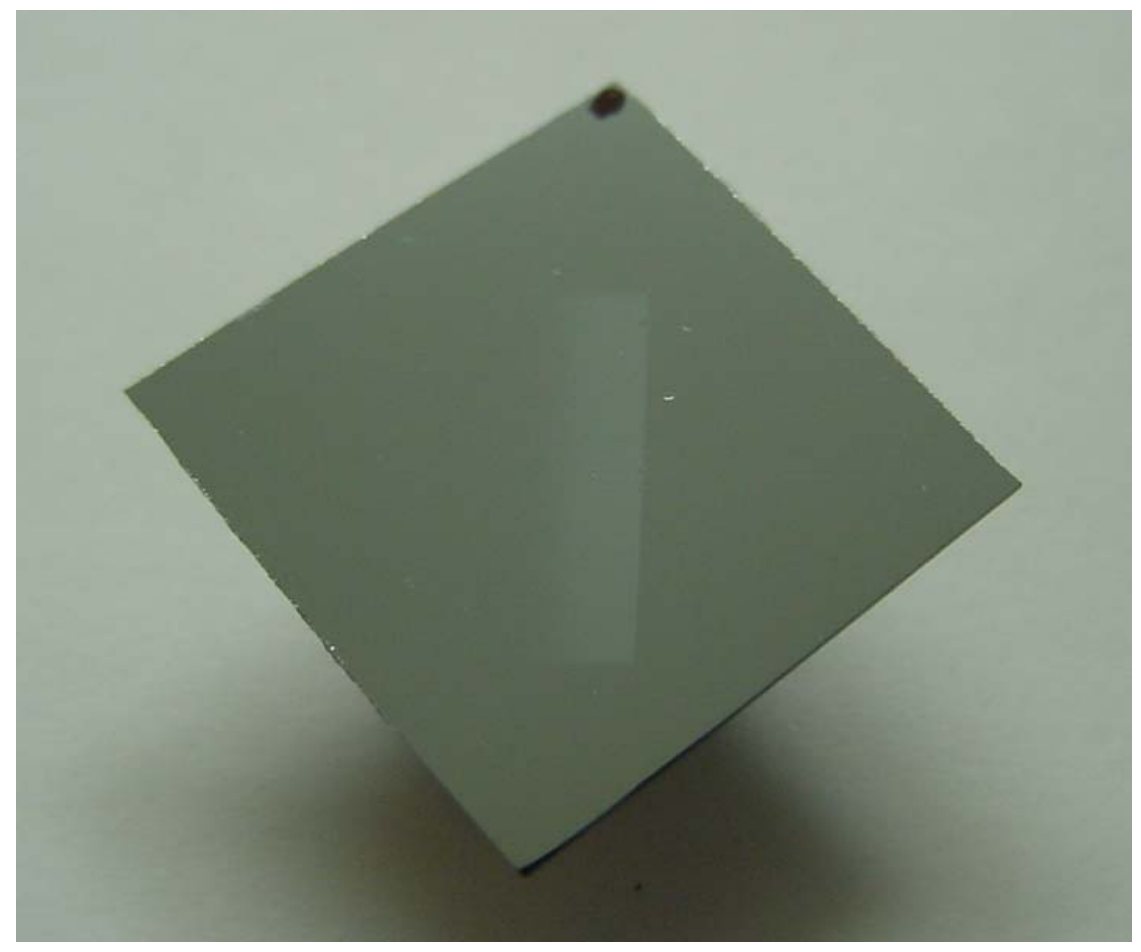

Figure 2.6. Photograph of large Si target following implantation with ${ }^{84} \mathrm{Kr}$. The $\mathrm{Kr}$ beam is evidenced by the lighter-colored rectangular area in the center.

An initial implant/release run was conducted on 4/5/01 using the new target assembly and a new piece of $\mathrm{Cu}$ foil, and the foil was positioned $\sim 1.3 \mathrm{~cm}(\sim 0.5 \mathrm{in}$.) behind the $\mathrm{FC}$ assembly $(\sim 4.0 \mathrm{~cm}[\sim 1.6$ in.] from the spectrometer exit slit). As indicated in Table 2.1, this run indeed showed an improved $\mathrm{Kr}$ release fraction $(\sim 71 \%)$; however, the release efficiency was still less than optimum. A rough calculation of the predicted beam size at this closer location suggested dimensions of $\sim 0.08 \times 0.8 \mathrm{~cm}(\sim 0.03 \mathrm{x} \sim 0.33$ in.). Given that the exposed $\mathrm{Cu}$ foil target diameter was only $\sim 1.0 \mathrm{~cm}(\sim 0.4 \mathrm{in}$.), it was decided at this point to make several additional modifications. These included replacing the double-side conflat fitting supporting the target/heater rod with an adjustable bellows-sealed off-axis port aligner and fabricating a new larger diameter ( $1.9 \mathrm{~cm}[\sim 0.75 \mathrm{in}]$.$) solid copper target. The gimbal device allowed for \mathrm{r}, \theta$ alignment of the target assembly push rod over an angle of up to $2^{\circ}$. A photograph of the modified target and button-heater assembly with the larger $\mathrm{Cu}$ target is shown in Figure 2.7. 


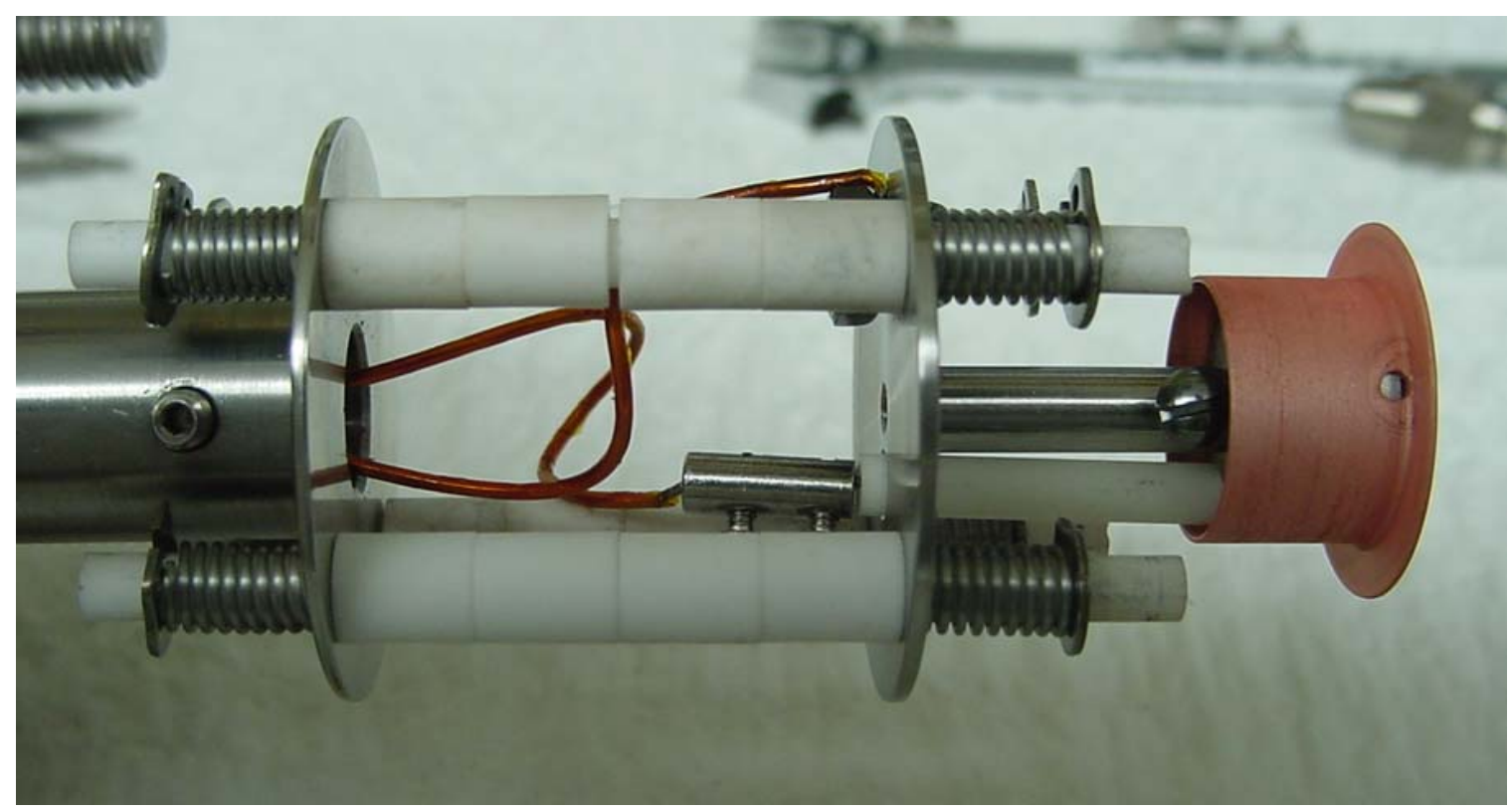

Figure 2.7. Modified "Floating" Button-Heater and Rod Assembly, with the Larger Cu Target Shown on the Right-Hand Side

With these additional modifications, a new series of implant $/$ release tests were conducted at $\sim 1.3 \mathrm{~cm}$ ( $\sim 0.5$ in.) from the FC assembly, beginning on 4/12/01. The results of these runs are listed in the bottom section of Table 2.1 and also shown separately in Figure 2.8. As is evident, for implant doses less than $\sim 10^{13}$ atoms, the new larger target yielded release efficiencies of very close to $100 \%$, indicating essentially complete capture and release of the $\mathrm{Kr}$ ion beam. Above this level, the release efficiency began to drop, indicating some onset of saturation effects for the smaller beam size at this location. From an estimated beam size of $0.8 \mathrm{~mm} \times 8 \mathrm{~mm}$ ( $0.03 \times 0.33 \mathrm{in}$.), an implantation fluence at the onset of saturation effects is calculated to be $\sim 2 \times 10^{14}$ atoms $/ \mathrm{cm}^{2}$, which is consistent with data observed for 1$\mathrm{keV}$ Ar ions in single-crystal $\mathrm{Cu}$ [100] (Carter et al. 1980).

\subsection{Measurement Uncertainties}

Both systematic bias and statistical uncertainties were present in the measurements of Kr implantation and release. The various uncertainty and bias components are summarized in Table 2.2. The two largest uncertainty components are the determination of the total integrated implant dose and the estimated uncertainty in the absolute accuracy of the faraday cup assembly. Since the faraday cup is used for both the implant and the release measurements, any systematic uncertainty in the FC data will affect the total atom determinations in Table 2.1, but not the Kr-release fractions in the last column. This assumes, of course, that both the FC and the electrometer are linear over the present range of currents measured, i.e., $\sim 10^{-12}$ to $\sim 10^{-9}$ amps. The linearity of the FC response at various electrometer sensitivities and for various values of the electrometer feedback resistor was measured using the $\mathrm{Kr}$ spiking system. These measurements indicate small systematic effects, but the standard deviation of five measured sensitivity values was only $1 \%$ (total spread was $2.3 \%$ ). At present, no corrections for any bias in the FC detection system have been made. This issue can be addressed more carefully in follow-on work should accuracies 
better than those reported here be required. For the present work, a conservative estimate of possible FC bias of $5 \%$ has been assumed.

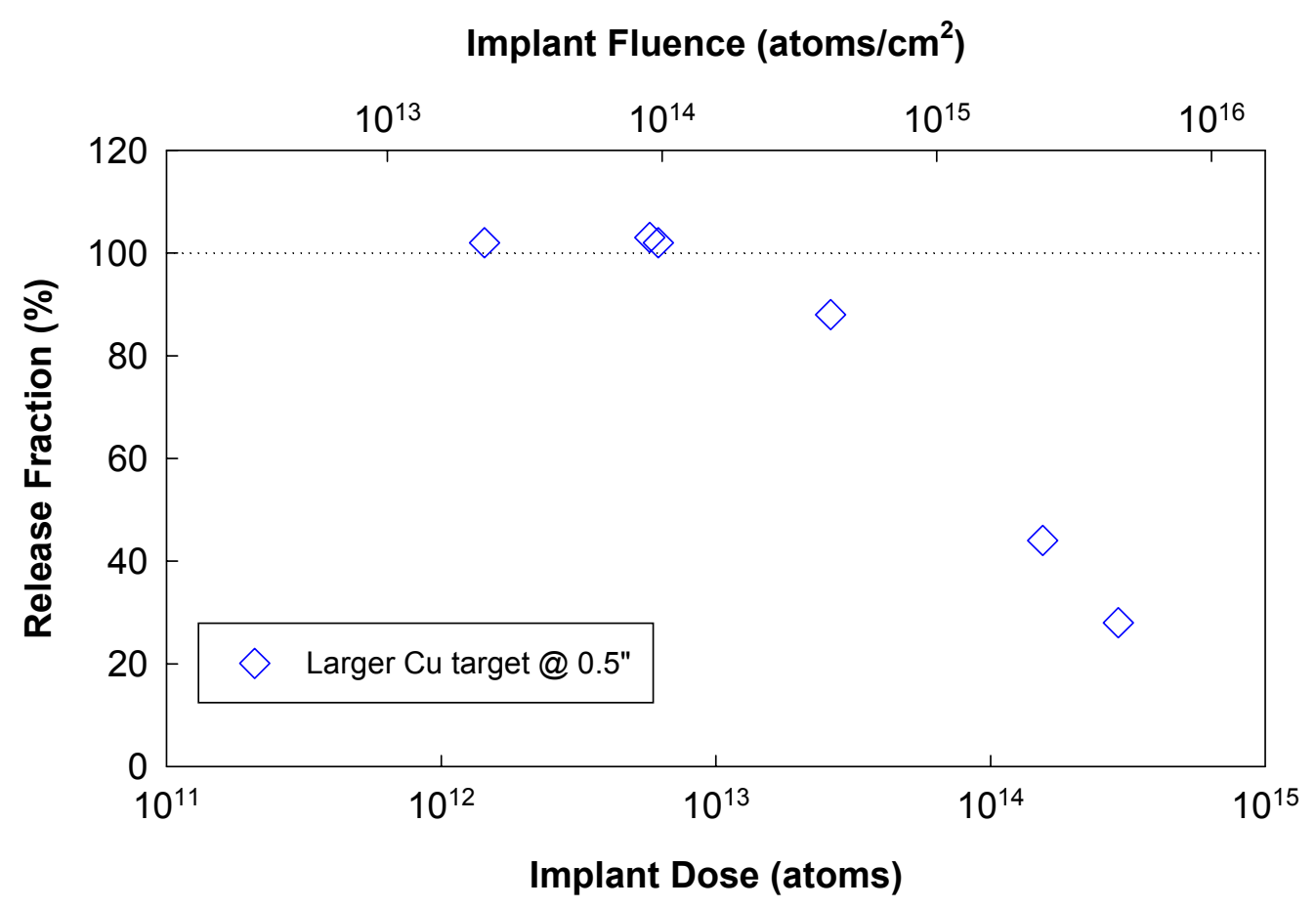

Figure 2.8. Measured Krypton Release Fraction Versus Implant Dose and Fluence for the Larger Copper Target at $\sim 1.27 \mathrm{~cm}(\sim 0.5$ in.) Behind the Faraday Cup Assembly

With regard to the determination of the total integrated dose, as was discussed earlier, the beam current could only be monitored by the 6-60 FC at the beginning and end of the target implantation. The general procedure was to leak in $\mathrm{Kr}$ to achieve the desired beam current and then let the system stabilize for several minutes before withdrawing the FC and allowing the beam to impact the target. For reasons that are not entirely clear, but probably related to relaxation of the leak-valve diaphragm, the beam signal would generally follow a decreasing curve for the first 5 to $10 \mathrm{~min}$. and then decrease in proportion to the slow pressure drop in the 3 -L storage volume. To determine the total integrated beam current, it was necessary to interpolate the beam current between the beginning and ending readings. 
Table 2.2. Sources of Bias and Imprecision in $\mathrm{Kr}$ Implantation/Release Measurements

\begin{tabular}{|c|c|c|}
\hline \multirow[b]{2}{*}{ Parameter (units) } & \multicolumn{2}{|c|}{ Estimated } \\
\hline & Bias (\%) & Precision $(1 \sigma)(\%)$ \\
\hline \multicolumn{3}{|l|}{ Implantation: } \\
\hline Faraday Cup absolute calibration (Amp) & 5 & not measured \\
\hline Electrometer Measurement (Amp) & $<1$ & 1 \\
\hline Interpolated Implant Dose (atoms) & $<1$ & 4 \\
\hline \multicolumn{3}{|l|}{ Release: } \\
\hline Faraday Cup absolute calibration (Amp) & 5 & not measured \\
\hline Krypton Release Measurements (Amp) & $<1$ & $<1-3^{(\mathrm{a})}$ \\
\hline 6-60 Sensitivity (Amp/atom) & 1 & 1 \\
\hline
\end{tabular}

An example of a typical beam profile is shown in Figure 2.4 for the implant run on $2 / 28 / 01$. For this implant, the beam current was $1.75 \mathrm{nA}$ at the beginning of the run and $1.52 \mathrm{nA}$ at the end. The curve between the beginning and ending data is a best fit to a power function. Integration under the curve yielded a total implant dose of $1.43 \times 10^{13}$ atoms. As is evident, the total integrated dose is somewhat dependent on the assumed shape of the beam-current profile during the implant. An assumption of a linear trend between the start and end of the run would have yielded an implant dose of $1.47 \times 10^{13}$ atoms, an increase of $\sim 3 \%$. Conversely, an assumption of a sharper initial dropoff in the beam current would predict a slightly smaller dose. Therefore, an error of $\sim 4 \%$ is conservatively assumed in the integrated dose values.

Most blocks of data where only a single parameter is varied (typically dose) show variability in the range of about $1 \%$. Examples include the three runs that gave $\sim 100 \%$, the four " $53 \%$ " runs done between $2 / 2 / 01$ and $2 / 26 / 01(53,53,53,52)$, and the three " $50 \%$ " runs done between $1 / 24 / 01$ and 1/26/01.

Combining the various uncertainties in Table 2.2 in quadrature yields an overall uncertainty estimate in the release percentage measurements of approximately 5\%. This estimate is not inconsistent with either the absolute release fractions observed or the variability in the release-fraction data. 


\subsection{Discussion and Conclusions}

A system and a method providing for measured implantation and release of rare-gas ions in metal foils have been developed. Implantation and release measurements were performed with a static mass spectrometer. Problems with an initial system led to the design of a second system with a "load lock" and gas manifold attached to the mass spectrometer. This allowed for easy withdrawal and isolation of the target/heater assembly from the mass spectrometer after implantation without the need to vent the mass spectrometer. The gas manifold also permitted evacuation and return of the mass spectrometer to baseline background after ion implantation as well as scrubbing the released gas from interfering gases.

A number of initial $\mathrm{Kr}$ ion implantation runs were made to determine efficiencies of the implantation/release of $\mathrm{Kr}$. Because these first runs, conducted with variable $\mathrm{Kr}$ ion beam currents, gave variable implant/release efficiencies from about $50 \%$ to $70 \%$, subsequent runs were conducted at constant beam currents. Implantation/release efficiencies for these runs were essentially constant at an average value of about $52 \%$. Through a series of experiments, it was established that this low value was due to only partial interception of the ion beam by the target. To correct for this, modifications were made to the gas-manifold system, mass spectrometer, and to the size of the target. These changes were successful in raising implantation/release efficiency values to essentially $100 \%$.

Further experiments were run to determine at what increasing value of $\mathrm{Kr}$ ion fluence implantation efficiencies would start to fall below $100 \%$ as a result of ion beam/target processes (e.g., sputtering effects, $\mathrm{Kr}$ diffusion, and radiation damage in the $\mathrm{Cu}$ target). Three implantations were performed at higher fluences than those at which $100 \%$ implantation efficiencies had been previously obtained. Extrapolation of implantation efficiencies of these three highest doses back to $100 \%$ efficiency indicated a dose value of $\sim 10^{13}$ ions of $\mathrm{Kr}$ as the threshold for measurable loss of implanted $\mathrm{Kr}$ with increasing dose. This dose value corresponds to a fluence value of $\sim 2 \times 10^{14}$ atoms $/ \mathrm{cm}^{2}$ as calculated from the ion beam size estimated from its image on a silicon wafer. This threshold fluence value is consistent with data in Carter et al. (1980).

Successful development of a method for $100 \%$ implantation/release efficiency of isotopically separated $\mathrm{Kr}$ ions in $\mathrm{Cu}$ foil accomplishes the first of two phases of a project for developing an ultrasensitive (10 parts per trillion) method to determine the isotopic content of rare gases. In the second phase, static mass spectrometric methods will be developed that will provide highly efficient isotopic separation of rare gas ions. Such methods will be applied to the implantation of separated rare-gas isotopes and subsequent isotopic analysis of implanted separated isotopes. 


\subsection{References}

Bahcall, J. N., and R. K. Ulrich. 1988. "Solar models, neutrino experiments, and helioseismology." Rev. Mod. Phys. 60, 297.

Bailey, K., C.Y. Chen, X. Du, Y.M. Li, Z.-T Lu, T.P. O’Connor, and L. Young. 2000. “ATTA-A new method of ultrasensitive isotope trace analysis.” Nucl. Instrum. Methods Phys. Res. 172, 224.

Ballou, N. E. 1999. Ion Implantation and Analysis of Rare Gases in Metal Foils, PNNL-13088, Pacific Northwest National Laboratory, Richland, Washington.

Carter, G., and Colligon, J. S. 1968. Ion Bombardment of Solids, American Elsevier Publishing Co., Inc., New York, NY.

Carter, G., Armour, D. G., Donnelly, S. E., Ingram, D. C., and Webb, R. P. 1980. "The injection of inert gas ions into solids: their trapping and escape." Rad. Effects, 53, $143-174$.

Chen, C. Y., Y. M. Li, K. Bailey, T. P. O’Connor, L. Young, and Z.-T. Lu. 1999. "Ultrasensitive isotope trace analyses with a magneto-optical trap." Science 286, 1139-1141.

Collon, P., T. Antaya, B. Davids, M. Fauerbach, R. Harkewicz, M. Hellstrom, W. Kutschera, D. Morrissey, R. Pardo, M. Paul, B. Sherrill, and M. Steiner. 1997. "Measurement of ${ }^{81} \mathrm{Kr}$ in the atmosphere." Nucl. Instrum. Methods Phys. Res. B, 123, 122-127.

Collon, P., D. Cole, B. Davids, M. Fauerbach, R. Harkewicz, W. Kutschera, D.J. Morrissey, R. C. Pardo, M. Paul, B.M. Sherrill, and M. Steiner. 1999. "Measurement of the long-lived Radionuclide ${ }^{81} \mathrm{Kr}$ in Prenuclear and Present-day Atmospheric Krypton." Radiochim. Acta, 85, 13-19.

Collon, P., W. Kutschera, H. H. Loosli, B. E. Lehmann, R. Purtschert, A. Love, L. Sampson D. Anthoney, D. Cole, B. Davids, D. J. Morrissey, B. M. Sherrill, M. Steiner, R. C. Pardo, and M. Paul. 2000. “ ${ }^{\circ 1} \mathrm{Kr}$ in the Great Artesian Basin, Australia: a new method for dating very old groundwater." Earth Planet. Sci. Lttr., 182, 103-113.

Davis, R., Jr., A. K. Mann, and L. Wolfenstein. 1989. "Solar neutrinos.” Annu. Rev. Nucl. Part. Sci., 39, 467.

International Atomic Energy Agency (IAEA). 1992. Isotopes of Noble Gases as Tracers in Environmental Studies. In: Proceedings of a Consultants Meeting on Isotopes of Noble Gases as Tracers in Environmental Studies, Vienna, Austria.

Kramer, S. D. et al. 1986. Nucl. Instrum. Methods Phys. Res. B, 17, 395.

Nakleh, C. W., R. T. Perry, J. Poths, W. D. Stanbro, W. B. Wilson, and B. L. Feary. 1997. "Noble gas atmospheric monitoring for international safeguards at reprocessing plants." In: Proc. Int. Workshop Status Meas. Techn. Identification Nucl. Signatures, Inst. Ref. Materials Meas.; 38th annual meeting of the Institute of Nuclear Materials Management, (July 20-24, 1997) Phoenix, Arizona, 159-174. 
Nier, A.O.C. 1940. "Mass Spectrometer for Routine Isotope Abundance Measurements." Rev. Sci. Instrum. 11, 212-216.

Ocker, K., and N. Thonnard. 1997. "The path to krypton and xenon isotope measurements from fewmicron sized samples; I. A low-blank gas extraction system." In: Twenty-eighth Lunar and Planetary Science Conference, 28, 1037-1038.

Oeschger, H. 1987. “Accelerator mass spectrometry and ice core research.” In: Fourth international symposium on accelerator mass spectrometry, Ontario, Canada. In: Nucl. Instrum. Methods Phys. Res. B, 29:1/2, 196-202.

Payne, M. G., Deng, L, and Thonnard, N. 1994. "Applications of Resonance Ionization Mass Spectrometry.” Rev. Sci. Inst. 1994, 65, 2433-2459.

Petit, J. R.; J. Jouzel, D. Raynaud, N. I.Barkov, J.-M. Barnola, I. Basile, M. Bender, J. Chappellaz, M. Davis, G. Delaygue, et al. 1999. "Climate and atmospheric history of the past 420000 years from the Vostok ice core, Antarctica.” Nature, 399, 429-436.

Poths, J., and E. P. Chamberlin. 1995. "A high efficiency ion source for $\mathrm{Kr}$ and Xe isotopic measurements.” Int. J. Mass Spectrom., 146/147, 47.

Thonnard, N. 1995. "Resonance Ionization of Heavy Noble Gases: The Potential of Krypton and Xenon Measurements from Single Presolar Grains" Meteoritics, 30, 588.

von Hippel, F., D. H. Albright, and B. G. Levi. 1985. "Stopping the production of fissile materials for weapons." Sci. Am., 253, 40-47.

Wendt, K., N. Trautmann, and B. A. Bushaw. 2000. "Resonant laser ionization mass spectrometry: an alternative to AMS?" Nucl. Instrum. Methods Phys. Res. B, 172, 162-169. 


\section{Distribution}

No. of

Copies

\section{OFFSITE}

3 S. A. Schubert

U.S. Department of Energy

Office of Nonproliferation \& National Security (NN-20)

1000 Independence Avenue, S.W.

Washington, D.C. 20585
No. of

Copies

\section{ONSITE}

DOE, Richland Operations Office/STP

R. L. Stutheit K8-50

39 Pacific Northwest National Laboratory

N. E. Ballou (10)

P7-07

C. J. Barinaga

P7-07

B. D. Cannon

K5-25

R. G. Clemmer

K6-48

W. C. Cosby

K1-01

G. C. Eiden (10)

P7-07

R. C. Hanlen

K8-41

S. G. McKinley

P7-07

B. M. Oliver (10)

P7-22

J. F. Wacker

P7-07 